\title{
Prediction of the Inductance in a Synchronous Linear Permanent Magnet Generator
}

\author{
Boel Ekergård ${ }^{1}$, Rafael Waters ${ }^{2}$, Mats Leijon ${ }^{1}$
}

\author{
${ }^{1}$ The Division for Electricity, Uppsala University, Uppsala, Sweden; ${ }^{2}$ The Wave Energy Converter Department, The Wave Energy \\ Company Seabased Industry AB, Uppsala, Sweden. \\ Email: Boel.Ekergard@angstrom.uu.se
}

Received February $11^{\text {th }}, 2011$; revised March 21 ${ }^{\text {st }}, 2011$; accepted March $31^{\text {st }}, 2011$.

\begin{abstract}
This paper presents calculations of the varying inductances profile for a synchronous linear surface mounted permanent magnet generator in an $A B C$ reference system. Calculations are performed by utilizing the reluctance term, known from analytic calculations and finite element method simulations. With the inductance term identified, the voltage difference between the generator's no load and load voltage can be calculated and an external circuit can be designed for optimal use of the generator. Two different operation intervals of the linear generator are considered and the results are discussed. The result indicates that time costly finite element simulations can be replaced with simple analytical calculations for a surface mounted permanent magnet linear generator.
\end{abstract}

Keywords: Wave Power, Synchronous Linear Permanent Magnet Generator, Varying Inductance, ABC of Frame Reference

\section{Introduction}

Researchers all over the world are looking for ways to convert electricity from new renewable energy sources. Wave energy is at the present time a relatively unexploited energy source, but has a potential to make a significant contribution to electrical power generation [1]. Over the past 25 years a large variety of concepts for wave energy conversion have been proposed and a significant number of different technologies have been suggested [2].

The presented paper discusses a direct driven point absorber, with a linear permanent magnet generator placed on the ocean floor, see Figure 1. The main dimensions of the generator is presented in Table 1. The output characteristics are referring to a nominal load condition, when the translator is moving at a constant speed of $0.7 \mathrm{~m} / \mathrm{s}$. The three phases are Y-connected to a resistive load at $12 \mathrm{ohm}$. For more information and literature about the system, see [3].

To investigate the inductance terms of a synchronous machine, experimental tests, such as standstill frequency response or short circuit test, are usually performed [4].
These tests are, however, impossible to perform at the design stage, so to be able to estimate the unknown parameter the authors have chosen to work with both analytic calculations and a numeric two-dimension finite element model.

\section{Analytical Model}

If the generator is connected to a balanced three phase load, each phase flux linkage can be expressed as [5]:

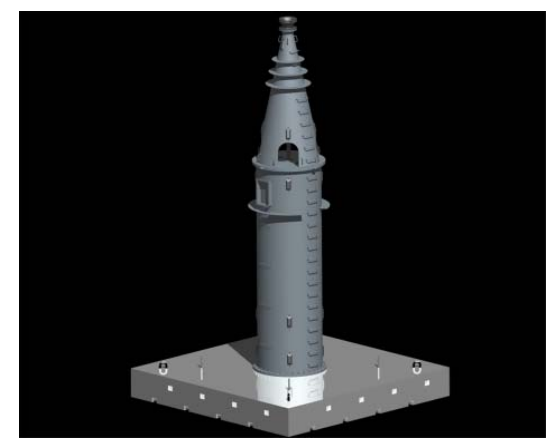

Figure 1. Schematic figure of the linear generator implemented in the system. 
Table 1. Main Dimensions of the Generator.

\begin{tabular}{lc}
\hline Output power & $20 \mathrm{~kW}$ \\
Armature current & $25 \mathrm{~A}$ \\
Phase to phase Voltage & $450 \mathrm{~V}$ \\
Fundamental frequency & $6 \mathrm{~Hz}$ \\
Stator length & $2000 \mathrm{~mm}$ \\
Translator length & $3000 \mathrm{~mm}$ \\
Stroke length & $2000 \mathrm{~mm}$ \\
\hline
\end{tabular}

$$
\begin{aligned}
& \lambda_{a}=L_{a a} \lambda_{a}+L_{a b} I_{b}+L_{a c} \lambda_{c}+\lambda_{P M, a} \\
& \lambda_{b}=L_{b b} I_{b}+L_{a b} I_{a}+L_{b c} I_{c}+\lambda_{P M, b} \\
& \lambda_{c}=L_{c c} I_{c}+L_{b c} I_{b}+L_{a c} I_{a}+\lambda_{P M, c}
\end{aligned}
$$

$L_{a a}, L_{b b}$ and $L_{c c}$ represent the winding's self inductance per phase, $L_{a b}, L_{a c}$ and $L_{b c}$ the winding's mutual inductance, $I_{a}, I_{b}$ and $I_{c}$ represent each phase current and $\lambda_{P M}$ correspond to the flux linkage from the permanent magnet [5].

The winding's self inductance, derived from Faraday's law of induction, is frequently expressed by the following expressions [5]:

$$
\begin{aligned}
& L_{a a}=L_{b b}=L_{c c}=L_{S}+L_{\text {leakage }} \\
& L_{S}=\frac{\mu_{0} A N^{2}}{l_{\text {air }}} * N_{\text {poles }}
\end{aligned}
$$

where $A$ corresponds to the winding-turn area, $N$ the number of turns, $N_{\text {poles }}$ he number of poles in the generator, $\mu_{0}$ the permeability of air and $l_{\text {air }}$ represent the length of the magnetic flux in air, i.e., in the air gap.

To calculate the mutual inductance in a balanced three phase generator knowledge of the winding-design, i.e., how the different phase's linkage flux intersect, is required. In this case, the windings are separated by $\alpha= \pm \frac{2 \pi}{3}$, and the mutual inductance can hence be calculated by [4]:

$$
L_{a b}=L_{a c}=L_{b c}=L_{S} \cos \left( \pm \frac{2 \pi}{3}\right)=-\frac{L_{S}}{2}
$$

To identify the linkage flux from the permanent magnet, $\lambda_{P M}$, and thereby be able to calculate the mutual inductance between the stator and translator, $L_{P M}$, the value of the magnetic field density, $B$, in the air gap is utilized. The analytic expression for the term is:

$$
B=\frac{B_{r} l_{P M}}{\mu_{r}\left(l_{\text {air }}+\left(\frac{l_{F e} A_{\text {air }}}{\mu_{F e} A_{F e}}\right)+\left(\frac{l_{P M} A_{\text {air }}}{\mu_{r, p} A_{P M}}\right)\right)}
$$

$B_{r}$ and $\mu_{r, p}$ represent the remanence magnetization and the recoil permeability of the permanent magnet, $l_{F e}, l_{P M}$ and $l_{\text {air }}$ represent the flux length in the highly magnetized part of the iron, in the permanent magnet and in the air gap and the terms $A_{a i r} A_{F e}$ and $A_{P M}$ are the active cross sections areas [6].

The flux linkage and the mutual inductance between the stator and translator, $L_{P M}$ can thereby be calculated according to

$$
\begin{aligned}
& \lambda_{P M}=N=N \int B d A \\
& L_{P M}=\frac{I_{P M}}{\lambda_{P M}}
\end{aligned}
$$

The current term, $I_{P M}$, represent the permanent magnet's equal current density, given by $B_{r}, l_{P M}$ and the permeability of air and the permanent magnet, $\mu_{0}$ respectively $\mu_{r}$, see Equation (10) [7].

$$
I_{P M}=\frac{B_{r} l_{P M}}{\mu_{0} \mu_{r}}
$$

With the amplitude and known cycle of the term $L_{P M}$ known, the induced voltage can be calculated by:

$$
U=L_{P M} \frac{d I_{P M}}{d t}
$$

Due to the relative motion between the stator and translator, the external surrounding for both the winding and the magnets changes continuously. To investigate how the different inductance terms are affected by the change of the external factors, for example the magnetic flux or the change of the reluctance in the magnetic circuit etc, simulations in a finite element simulation tool have been performed.

\section{Numerical Model}

To be able to apply the finite element method, the area of investigation, in this case the two dimensional model of the generator, is divided into small regions, called elements. It is assumed that the unknown quantities, for example the vector potential $A$, in each element can be described by a simple function, i.e., a polynomial. The order of the polynomial determines the order of the element [8]. In the finite element simulation tool the authors have chosen to work with, each element is describe as a second order triangular, see Figure 2. Each element is thereby described by a second order polynomial, see Equation (12).

$$
A=a+b x+c y+d x y+e x^{2}+f y^{2}
$$

The $x$ - and $y$ - term define the element's position in the two dimensional $x y$-plane, and the terms $a$ to $f$ are the unknown amplitudes of the investigated quantities. 


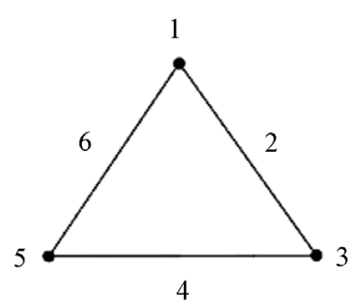

Figure 2. The second order element.

The physical interpretation of the second order equation is that the unknown quantities are assumed to only vary quadratic-ally in each direction [8].

The working approach of the chosen finite element simulation tool, is to define the vector potential, $A$, in each element. By evaluating the vector potential in each of the six points, see Figure 2, all six coefficients in the element's polynomial is found. Each element's potential can thereby be approximately calculated by Equation (12). When the vector potential in all elements is known, the magnetic flux in the generator can be calculated by [6]:

$$
\Phi=\int(\nabla \times \boldsymbol{A}) \mathrm{d} \boldsymbol{a}=\boldsymbol{A} \cdot \mathrm{d} \boldsymbol{s}
$$

The current density in a conducting region, $J_{z}$, can be expressed as [6]:

$$
\nabla^{2} A_{z}=-\mu_{0} J_{z}
$$

With the unknown parameters defined, the simulations are straight forward.

\section{The Machine Model}

To have a unique solution, the model must be limited by boundary conditions. These conditions may be describing the continuity or points, lines and surfaces in the model with known values of potential and field [8]. The single boundary condition the authors have chosen to work with, presented in Figure 3, states that there is no fringing of the magnetic field at infinity.

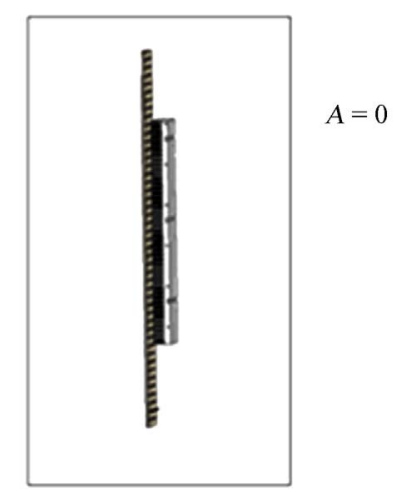

Figure 3. The chosen boundary condition.

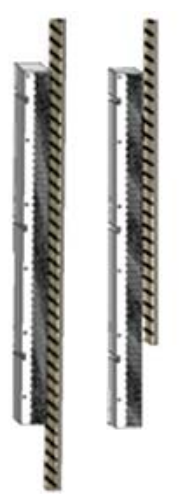

Figure 4. a) Interval I, b) Interval II.

With a translator stroke length of $2 \mathrm{~m}, 1 \mathrm{~m}$ in each direction, the active area changes after half of the stroke length, and the generator's operation is divided in to two intervals. During Interval I, a magnet simultaneously slips in and out of the stator, resulting in a constant active stator area. During Interval II, presented in Figure 4(b), the active area decreases as the outmost magnet slips out of the stator. During Interval II, the total flux linkage in the machine is thereby not only varying due to the phenomena with changing amplitude of the flux linkage from the magnet trough the winding area, but also due to a varying size of the active area.

\section{Results}

The calculated values, resulting from the analytical model, of the different parameters are presented in Table 2 together with a measurement on an existing prototype of the studied generator.

To investigate how the calculated values vary due to the relative motion between the stator and translator, finite element simulations were performed. The following presented results are from simulations, performed with a constant speed of the translator at $0.7 \mathrm{~m} / \mathrm{s}$ with the generator operating at No Load.

Figure 5 presents the inductance in the generator during Interval I. By Equation (11) the induced No Load voltage for phase a) was calculated, see Figure 6.

Table 2. The results from the analytic calculations and measured on the real machine.

\begin{tabular}{ll}
\hline Parameter & Value \\
\hline$I_{P M}$ & $2380 \mathrm{~A}$ \\
$L_{P M, \text { Calculated }}$ & $10.3 \mathrm{mH}$ \\
$L_{S, \text { Calculated }}$ & $19.5 \mathrm{mH}$ \\
$L_{\text {Mutual,Calculated }}$ & $9.8 \mathrm{mH}$ \\
$L_{S, \text { Measured }}$ & $18.5 \mathrm{mH}$ \\
\hline
\end{tabular}




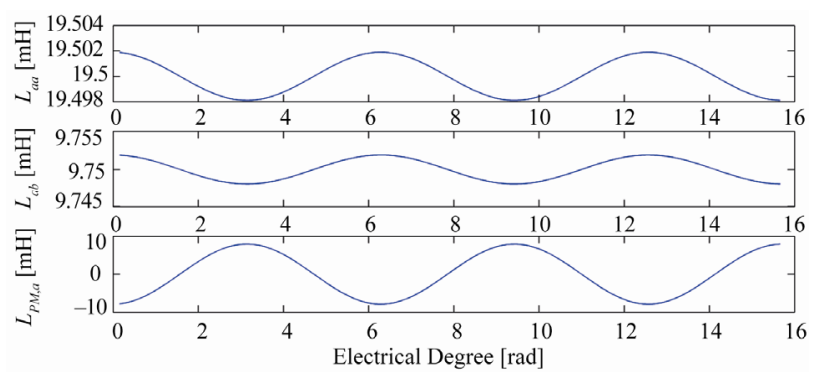

Figure 5. The upper graph presents the varying self inductance for one phase, the middle graph presents the varying mutual inductance each phase is exposed to from the two other phases, whereas the third graph presents the varying mutual inductance between the stator and translator, in terms of phase a.

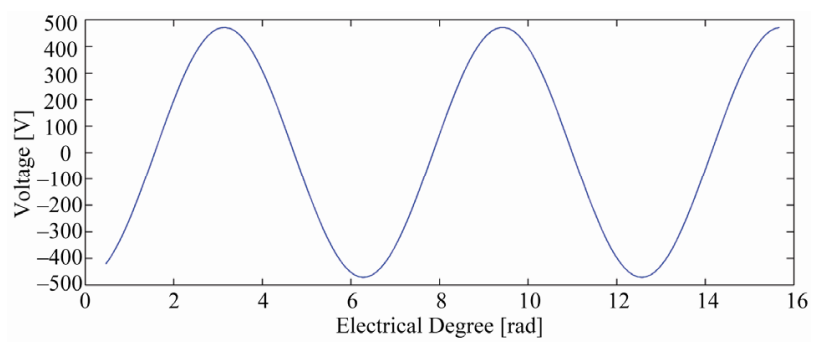

Figure 6. The induced No Load voltage for one phase at a constant speed of $0.7 \mathrm{~m} / \mathrm{s}$.

Let us take a look at what happens during Interval II. As the translator slips out of the stator, the active area and thereby the linked flux decreases. The part of the winding which is no longer covered by magnets loses the magnets flux linkage. Figure 7 presents the inductance terms in the generator during Interval II. By Equation (11) the induced No Load voltage for phase a) was calculated, and is presented in Figure 8.

\section{Discussion}

The used surface mounted permanent magnets have a relative permeability close to one, i.e., the same as air. The length, see Equation (5), for the flux in low permeability material does thereby neither decrease nor increase if the air gap decrease or increase. The winding's self- and mutual inductance is thereby not affected by the air gap, which is strength by the presented result. The calculations, simulations and experimental measurement indicate together that the winding's self- and mutual inductance is highly not affected by the translator's position, i.e., the distance the flux transfers in the low permeability material is neither shorter or longer despite the change of the translator's position. However, the authors don't think this is the case if the low permeability permanent magnets are replaced with higher permeability-material, for example pole shoes of steel. The length for the flux in low per-

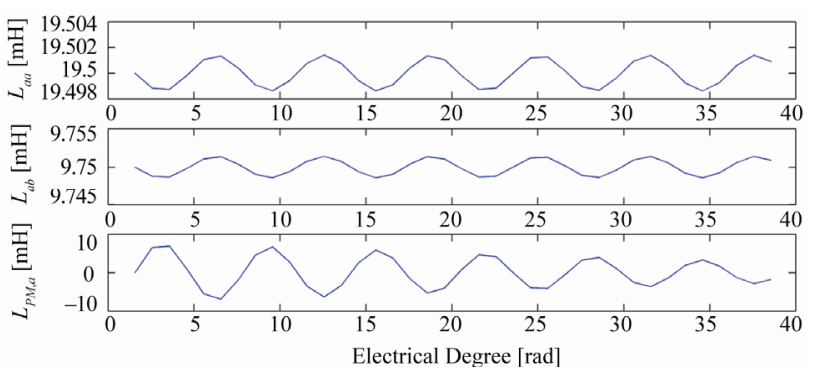

Figure 7. The upper graph presents the varying self inductance for one phase, the middle graph presents the varying mutual inductance each phase is exposed to from the two other phases, whereas the third graph presents the varying mutual inductance between the stator and translator.

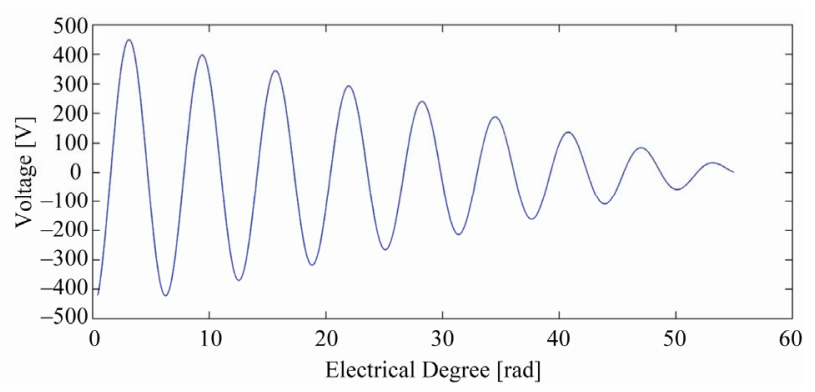

Figure 8. The calculated induced voltage for one phase.

meability material can thereby be increased or decreased by increase or decrease the air gap. The designer can thereby by external parameters reach the required value, within values, on the inductance term.

The mutual inductance between the stator and translator changes drastically both during one electrical period and with the active area. The value is, as expected, highly affected by the decreasing active area. During this paper, the reluctance in the iron in the magnetic circuit is neglected, with the motivation of the iron's high permeability compared to air. Furthermore, the almost identical results of the measured and calculated value of the windings self inductance, convinced the authors to neglect the winding's leakage inductance.

The decision to present the mutual inductance between the stator and translator as a signal oscillating around zero, Figures 5 and 7, was made to show the sign of the induced voltage. By this decision the direction of the coordinate system can be kept fixed during the full electric cycle. The physical meaning of a negative inductance does, of course, not exist, but the authors consider this representation to have pedagogic merits.

During the presented study the authors investigated different methods to examine the inductance terms of the machine, for example the Energy Perturbation Method, see $[9,10]$. However, the reduced opportunity to perform accurate analytical calculations were the reason the au- 
thors did not include the method in this paper.

\section{Conclusion}

An analysis of the varying inductance term in the $A B C$ reference frame for a permanent magnet linear generator has been presented in this paper. The analysis is based on analytical calculations that have been compared to experimental measurements, and simulations in a finite element method program. The analytical results of the winding's self inductance showed very good agreement with the experimental measurements on the physical machine, thus serving as a reminder that time costly simulations are not always necessary. The numerical simulations were used to study the inductance terms during translator movement. As expected, it has been shown that the mutual inductance between the stator and translator is very much affected by the translator's position. On the other hand, the results show that the winding's self- and mutual inductance is barely affected by the air gap or the translator's position. This is attributed to the non-changing distance that the flux travels in the low permeability material despite changes of the external parameters. The conclusion is that only the design of the winding and stator affects the size of the different winding inductance terms.

\section{Acknowledgements}

This research was carried out as part of the Statkraft Ocean Energy Research Program, sponsored by Statkraft (www.statkraft.no). This support is gratefully acknowledged. The authors would also like to thank The Swedish Research Council for their financial support.

The authors would like to thank Cecilia Boström for her revision on spelling and grammar and a special thanks to Hjalmar Nyström for his contribution on the mechanical design and construction of the generator.

\section{REFERENCES}

[1] L. Szabó, C. Oprea, I.-A. Viorel and K. Á. Biró, "Novel Permanent Magnet Tubular Linear Generator for Wave
Energy Converters," Electric Machines \& Drives Conference, IEMDC, IEEE International, Antalya, 3-5 May 2007, pp. 983-987.

[2] A. F. De O. Falcao, "Wave Energy Utilization: A Review of the Technologies," Renewable and Sustainable Energy Reviews, Vol. 14, No. 3, October 2009, pp. 899-918.

[3] M. Leijon, O. Danielsson, M. Eriksson, K. Thorburn, H. Bernhoff, J. Isberg, J. Sundberg, I. Ivanova, E. Sjöstedt, O. Ågren, K. E. Karlsspm and A. Wolfbrand, "An Electrical Approach to Wave Energy Conversion," Renewable Energy, Vol. 31, No. 9, July 2006, pp. 1309-1319. doi:10.1016/j.renene.2005.07.009

[4] R. Escarela-Perez, E. Campero-Littlewood and A. L. Laureano-Cruces, "Steady-State Inductance Calculation of a Turbine Generator in the ABC Reference Frame," International Conference on Electrical and Electronics Engineering, Mexico City, 5-7 September 2007, pp. 233236.

[5] F. Wu, X-P. Zhang, P. Ju and M. J. H. Sterling, "Modeling and Control of AWS-Based Wave Energy Conversion System Integrated Into Power Grid," IEEE Transactions on Power System, Vol. 23, No. 3, August 2008, pp. 11961204.

[6] K. Nilsson, O. Danielsson, and M. Leijon, "Electromagnetic Forces in the Air Gap of a Permanent Magnet Linear Generator at No Load," Journal of Applied Physics, Vol. 99, No. 3, 2 006, pp. 034505-034505-5.

[7] B. Bolund, "Electric Power Generation and Storage Using a High Voltage Approach," Ph.D. Dissertation, Acta Universitatis Upsaliensis, Uppsala, 2006.

[8] S.J. Salon, "Finite Element Analysis of Electric Machinery," IEEE Computer Applications in Power, Vol. 3, No. 2, 1990, pp. 29-32. doi:10.1109/67.53227

[9] S. R. Shaudhry, S. Ahmed-Zaid and N. A. Demerdash, "Coupled Finite-Element/State Space Modeling of Turbogenerators in the ABC Frame of Reference-The No Load Case," IEEE Transactions on Energy Conversion, Vol. 10, No. 1, March 1995, pp. 56-62.

[10] T. W. Nehl, F. A. Fouad, N. A. Demerdash, "Determination of Saturated Values of Rotating Machinery Incremental and Apparent Inductance by an Energy Perturbation Method," IEEE Transactions on Power Apparatus and System, Vol. PAS-101, No. 12, December 1982, pp. 4441-4451. 